\title{
Zahnärzte in Schlagzeilen...
}

...verheißen selten Gutes. Muss unser Berufstand doch häufig genug herhalten als Projektionsfläche für tief sitzende Ängste, als Zielscheibe für Angriffe auf sogenannte „Besserverdiener“, im Kino oder „Tatort“ häufig als Symbol für Verschlagenheit und Gier (für Cineasten: Ausnahmen sind natürlich Gunther Philipp oder Walter Matthau).

Dass die veröffentlichte Meinung einem Kollegen zur Seite springt, ist eher eine Ausnahme. So jetzt geschehen in der Bundeshauptstadt, die wahrlich viel zu bieten hat an Sensationen und Skandalen. Gunnar Schupelius hat sich in einem Kommen- tar in der B.Z. mit den Angriffen der Antifa auf unseren Kollegen Dr. Marius Radtke auseinander gesetzt.

Radtke ist Vorsitzender der Vertreterversammlung der KZV Berlin und stellvertretender Versammlungsleiter der Hauptversammlung des Freien Verbandes. Er engagiert sich Zeit seines Berufslebens ehrenamtlich und seit einiger Zeit auch in der Kommunalpolitik

Wir drucken den Kommentar ungekürzt nach aus Solidarität mit unserem Kollegen und ergreifen damit nicht Partei für eine Partei, sondern für einen zivilisierten Umgang miteinander.

Dr. Joachim Hüttmann, DFZ-Chefredakteur

\section{Linke jagen Berliner Zahnarzt und bekommen Geld vom Staat}

\author{
In der Pistoriusstraße in Weißensee behandelt der Zahnarzt Dr. Marius Radtke (64) seit vielen \\ Jahren seine Patienten. Marius Radtke arbeitet ehrenamtlich als Sprecher des Bezirksverbandes \\ Lichtenberg der Partei Alternative für Deutschland (AfD). Dadurch wurde er zur Zielscheibe linker \\ Gruppen, die beschlossen, ihm das Leben schwer zu machen. Sie steckten in der Nachbarschaft \\ der Praxis eine "Warnung" in die Briefkästen. So sollten die Patienten erfahren, dass ihr Zahnarzt \\ Mitglied "der rassistischen, unsozialen und heuchlerischen Partei AfD" sei. Dann belieferten sie \\ die übrigen Arztpraxen in der Umgebung und baten dort das "sehr geehrte Praxisteam", keine \\ Patienten mehr an Dr. Radtke zu überweisen.
}

So versuchte man seit dem 13. April, den Zahnarzt wirtschaftlich zu ruinieren. Auf ihrem „Portal antifaschistischer Initiativen" feierten sich die Linken dafür selbst, darunter das Motto: „Deutschland den Zahn ziehen!“

\section{Aufmarsch vor Zahnarztpraxis}

Dann, am Donnerstag, den 12. Mai, war es so weit: 60 schwarz gekleidete Menschen marschierten vor der Praxis des Zahnarztes auf. Die Polizei sicherte die Tür, hinter der Dr. Radtke den Bohrer hielt, während er von der Straße aus beschimpft wurde. Dieser Marsch zum Zahnarzt wurde unter dem Titel „Weißensee ist bunt“von drei Gruppen unterstützt. Eine davon war das „Willkommensnetzwerk Pankow Hilft“. Dieses Netzwerk wird finanziell von der Bundesregierung unterstützt und zwar vom Familienministerium. Bisher hatte sich „Pankow Hilft“ durch ehrenamtliche Arbeit für Migranten und Asylbewerber hervorgetan und ist dafür auch immer mal wieder lobend erwähnt worden. Nun tauchten die Helfer also in der Pistoriusstraße auf, nicht aber, um zu helfen, sondern um einen Zahnarzt zu beschimpfen, weil er Mitglied der AfD ist. Das alles geschah vor einer Woche. Die Öffentlichkeit erregte sich nicht nennenswert darüber. Und das ist vielleicht das Schlimmste. Denn wenn es Schule macht, dass Menschen wegen ihrer politischen Gesinnung von einer Meute bedrängt werden, mit dem Ziel, dass sie ihren Beruf nicht mehr ausüben können, dann ist die Demokratie am Ende. Dann werden wir sehr schnell in ein neues Zeitalter der Straßenkämpfe eintreten.

\section{Berliner Stadtoberhaupt hüllt sich in Schweigen}

Der Ministerpräsident von Thüringen, Bodo Ramelow (Linke), hat im April mit deutlichen Worten den Aufmarsch der Linksextremisten vor dem Wohnsitz von AfD-Landeschef Björn Höcke verurteilt. Ramelow sprach von „Nazi-Methoden“. Mit dieser Deutlichkeit hätte auch die Kampagne gegen den Berliner Zahnarzt verurteilt werden müssen. Doch hüllte sich unser Stadtoberhaupt in Schweigen.

Und auch von keinem anderen Politiker war ein Wort zu hören. Wer sich mit Dr. Radtke auseinandersetzen will, der möge ihn zur Diskussion einladen. Doch das wollen diese linken Marschierer offenbar gar nicht. Sie wollen einen Menschen fertigmachen, der ihnen nicht gefällt.

Gunnar Schupelius ist Mitglied der Chefredaktion der Berliner Tageszeitung B.Z. Dieser Kommentar ist in seiner B.Z.-Kolumne „Mein Ärger" am 18. Mai 2016 erschienen. 